\title{
Disease susceptibility in California sea lions
}

\section{Inbreeding influences the response of these animals to different pathogens in the wild.}

nbreeding in animals can increase their susceptibility to pathogens, but direct evidence from wild populations is scarce $^{1,2}$ and it is unclear whether all pathogens are affected equally. Here we analyse rescued California sea lions afflicted with a range of different pathogens, and find that sick animals have higher-thannormal parental relatedness, with the extent varying among disease classes. Our findings indicate that mortality in natural populations may not be entirely random and that inbred individuals could act as more effective reservoirs of infectious agents.

We sampled tissues from 371 stranded California sea lions (Zalophus californianus; Fig. 1) that were being rehabilitated at the Marine Mammal Center in Sausalito, California. Each individual was assessed for age category (based on length, pelage, sagittalcrest size and tooth development) and health status. We identified six classes of health problem ${ }^{3-6}$ : trauma (inflicted by boats, gunshot or net trapping), carcinoma, bacterial infection, helminth infection, intoxication by domoic acid as a result of ingesting prey contaminated by the toxinproducing alga Pseudonitzchia australis ${ }^{3}$, and 'nonspecific' (used to classify morbid sea lions with subclinical infections ${ }^{6}$ ). Animals suffering from trauma were considered as controls that were representative of the normal adult population.

All sea lions were scored for 11 highly polymorphic microsatellite DNA markers ${ }^{7-10}$ that were in Hardy-Weinberg equilibrium. Homozygous individuals were genotyped twice to guard against the possibility of allele drop-out. As a measure of inbreeding, we estimated the relatedness of an individual's parents by calculating an internal relatedness' factor ${ }^{11}$.

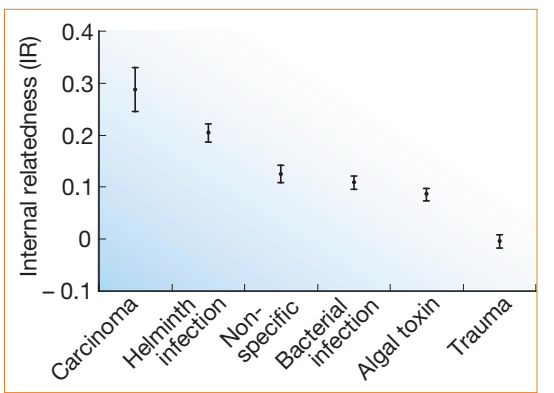

Figure 2 Internal relatedness in sea lions and the incidence of different disease classes. Carcinoma, $n=13$; helminth infection, $n=72$; nonspecific, $n=51$; bacterial infection, $n=98$; algal toxin, $n=101$; trauma (control), $n=36$. Values are means \pm s.e. The mean internal relatedness value of trauma animals $(-0.004)$ is indistinguishable from zero, as would be expected for individuals born to randomly mated parents ${ }^{5}$
Mean internal-relatedness values varied significantly among the six different disease classes (analysis of variance (ANOVA): $F_{5,370}=8.97, P=10^{-8}$ ), being lowest for trauma and highest for carcinoma (Fig. 2). A generalized linear model did not reveal any significant effect of sex or age class on internal relatedness and disease.

After trauma, the next-lowest internalrelatedness values are found for individuals affected by algal toxin. The difference in mean internal relatedness between trauma and toxin is significant (two-tailed $t$-test: $t=2.74$, d.f. $=135, P=0.007)$. Removal of these two non-infectious disease classes does not eliminate interclass differences (ANOVA: $F_{3,233}=5.66, P=0.0009$ ).

For stringent comparison between infectious agents, we also removed carcinoma (although not an infectious disease, it is strongly associated with herpesvirus infection in sea lions ${ }^{4}$ ) and the nonspecific category because the sources of morbidity were not defined. This leaves bacterial infection (mean internal relatedness, 0.11 ) and helminth infection (mean internal relatedness, 0.20 ), for which the difference is significant between both groups (two-tailed $t$-test: $t=3.07$, d.f. $=168, P=0.002)$. Thus, the extent to which inbreeding increases susceptibility to infectious disease varies depending on the class of pathogen involved.

The trend that is evident in Fig. 2 indicates that an individual's susceptibility to a biochemically simple challenge, such as a toxin, may not be markedly affected by inbreeding; however, inbreeding seems to become an important factor in susceptibility to more complex, long-lived gut parasites that interact with many aspects of the host's biology. To test this possibility, we surveyed faecal eggs to determine the number of different types of helminth infection in affected sea lions, and found a significant positive regression of parasite diversity on inbreeding $\left(r^{2}=0.11, n=72, P=0.003\right)$. This indicates that the more inbred animals harbour a wider range of helminth infections.

To investigate whether a sick individual's parental relatedness also affects its response to treatment, we recorded the recovery times of animals with 'nonspecific' morbidity that were not receiving any treatment against a specific disease. We found a significant positive regression of rehabilitation time on inbreeding $\left(r^{2}=0.14, n=43\right.$, $P=0.01$ ), indicating that the more inbred individuals take longer to recover.

All of the challenges (apart from trauma) that we studied were influenced by inbreeding, which supports findings that link

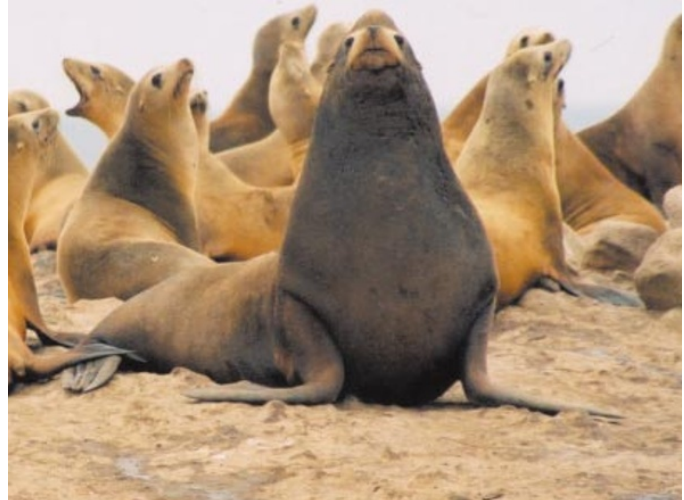

Figure 1 Bad breeding? Inbred sea lions' increased susceptibility to disease could pose a risk to their fellows as well as themselves.

heterozygosity of the major histocompatibility complex with an effective response to challenge (see ref. 12 , for example).

The importance of genetics in demography and conservation is contentious ${ }^{13}$. Our results indicate that the role of stochasticity in the natural mortality of vertebrates may be less important than was previously thought, and that inbreeding could have a significant impact on conservation programmes and the dynamics of wildlife diseases. The most inbred individuals not only cost more to treat and rehabilitate, but they could also act disproportionately as reservoirs of infectious agents when they are subsequently released.

Karina Acevedo-Whitehouse ${ }^{\star}$, Frances Gulland $\dagger$, Denise Greig $\dagger$, William Amos*

${ }^{\star}$ Department of Zoology, University of Cambridge, Downing Street, Cambridge CB2 3EJ, UK

e-mail:w.amos@zoo.cam.ac.uk

$\dagger$ The Marine Mammal Center, Marin Headlands, 1065 Fort Cronkhite, Sausalito,

California 94965, USA

1. Keller, F. \& Waller, D. M. Trends Ecol. Evol. 17, 230-241 (2002). 2. Coltman, D. W., Pilkington, J. G., Smith, J. A. \& Pemberton, J. Evolution 53, 1259-1267 (1999)

3. Gulland, F. M. D. et al. Vet. Rec. 150, 475-480 (2002).

4. Lipscomb, T. P. et al. Vet. Pathol. 37, 609-617 (2000).

5. Goldstein, T. et al. Aquat. Mamm. 25, 43-51 (1999).

6. Gage, L. J., Gerber, J. A., Smith, D. M. \& Morgon, L. E. J. Zoo Wild. Med. 24, 41-47 (1993).

7. Coltman, D. W., Bowen, W. D. \& Wright, J. M. Mol. Ecol. 5, 161-163 (1996).

8. Allen, P., Amos, W., Pomeroy, P. P. \& Twiss, S. D. Mol. Ecol. 4, 653-662 (1996).

9. Hoelzel, A. R., Campagna, C. \& Arnborm, T. Proc. R. Soc. Lond. B 268, 325-332 (2000).

10. Buchanan, F. C., Maiers, L. D., Thoe, T. D., DeMarch, B. G. \& Stewart, R. C. Mol. Ecol. 7, 1083-1085 (1998).

11. Amos, W. et al. Proc. R. Soc. Lond. B 268, 2021-2027 (2001).

12. Penn, D. J., Damjanovich, K. \& Potts, W. K. Proc. Natl Acad. Sci. USA 99, 11260-11264 (2002).

13. Frankham, R., Ballou, J. D. \& Briscoe, D. A. Introduction to Conservation Genetics (Cambridge Univ. Press, Cambridge, UK, 2002).

Competing financial interests: declared none 